\title{
Study Key Factors in Selecting Proper Location for Insurance Branches
}

\author{
Sahar Ataee Ashtiani ${ }^{1, ~ *, ~ A l i m o h a m a d ~ A h m a d v a n d ~}{ }^{2}$, Hossein Eghbali ${ }^{1}$ \\ ${ }^{1}$ Department of Industrial Engineering, University of Eyvanekey, Eyvanekey, Iran \\ ${ }^{2}$ University of Eyvanekey, Eyvanekey, Iran
}

Email address:

sahar.ataie@yahoo.com (S. A. Ashtiani), Alimohamadahmadvand@gmail.com (A. Ahmadvand), h.eghbali@eyc.ac.ir (H. Eghbali)

${ }^{*}$ Corresponding author

\section{To cite this article:}

Sahar Ataee Ashtiani, Alimohamad Ahmadvand, Hossein Eghbali. Study Key Factors in Selecting Proper Location for Insurance Branches. International Journal of Management and Fuzzy Systems. Vol. 4, No. 3, 2018, pp. 46-52. doi: 10.11648/j.ijmfs.20180403.12

Received: June 30, 2017; Accepted: September 12, 2018; Published: September 13, 2018

\begin{abstract}
Choosing the proper location is one of the most important implementation activities in industrial engineering for large-scale projects. So far, most researches has been done in this field. Location studies location is such important that today, it is used for places on the agenda, but these proceedings must be based on scientific approaches. Appropriate studies for location, in addition to the economic impact, has an influence on the performance of industrial units, social, environmental, cultural and economic affects in the constructed area. In this article we have tried to identify key factors to select proper place for insurance branches to be totally scientific, so that the ultimate decision maker ensures that the process of site selection be precise and comprehensive and make sure that it is not based on personal judgment. In this process it is important to consider all factors in location optimal insurance branches as well as the views of different interest groups in the deployment location.
\end{abstract}

Keywords: Location, Insurance Branches, Fuzzy Logic

\section{Introduction}

Facility location is trying to choose the best place to execute those activities that with existing material and intellectual resources available, have the highest efficiency to provide a predetermined target. Selecting a location among available locations require precise awareness of location environments using appropriate models and tools. Location theory by regulating key factors in decision-making and providing logical solutions, help decision-makers and planners in selecting the proper location or locations. In general, location principles intend to clear the relation between operators and effective variables in facility location and answer the question raised related to the most efficient place for industrial, commercial, service units etc. In general, one of the principles in the theory of location is determining the optimal location based on the least cost, where gains the most benefit from cost reduction. Location theories hold that by general rule mining based on the factors and variables affecting the location process, explain the existing structure of location industrial, commercial, service activities etc. and provide the best location. The meaning of theory of location is to present all the principles which by using them, industrial activities determines its optimal location in accordance with the maximum benefit. Center of gravity of location theory goes back to Germany. The oldest location model belongs to (Safle) in 1878, which presented his theory on gravity model [1].

Finding the proper places to start a business count as the most important steps is the executive projects. The final location should provide the necessary conditions and criteria as much as possible, because ignoring them will cause undesirable results. Also location is one of the spatial analysis that has an important role in reducing the costs of creating and launching various activities. That's why it is considered as one of the most important and effective implementation factor of projects. Nowadays the high functionality of hierarchical analysis methods for managing and analyzing spatial data resulted in a very environmentally efficient implementation of the different stages of analysis such as facility location. What that is important in this process is to consider all factors in location optimal insurance branches as well as the views of different interest groups in the deployment location. Therefore, a method must be 
submitted in selecting optimum branches that ensures all key factors in optimal location of insurance branches to be considered and also take beneficiary groups ideas into account. Thus by using these key factors we can ensure that decisions made about the optimality of desired location has high rigor and academic standing. Real-world problems typically have complex structure due to the uncertainty in the definition and understanding of them. Since human being was able to think, he has always faced with ambiguous in various social, technical and economic problems. Even the invention of the computer and developing its application in the analysis of real-world problems could not solve the problem of ambiguity and uncertainty. As a result, to select an appropriate location where the data are uncertain and fuzzy, fuzzy method should be used. On the other hand, one of the key problems managers and planners facing to allocate resources to areas that have the potential return on investment (ROI) and bring economic and social benefits for the community. These spots are selected using methods of location which in fact analyze the spatial and non-spatial talents of a country to select suitable specific location. Proper facility location is done when an accurate, rapid and standard assessment from attractive sights of places exist for users.

\section{Research Background}

Facility location is one of the key actions in the process of constructing of industrial or service units which considering this important factor, has a significant role in success of centers. In the field of problems of location, according to many researchers, such as Schmid and Doerner [2], considering location problems and differences take strength and between the more and algorithms and new solutions and combined solutions are presented to meet these problems. In general, one of the principles in the theory of location is determining the optimal location at the least cost. Which means the most profit is gained from cost reduction. (Lanhart) is known as one of the founders of this theory. He tried to express the manner of optimum facility location in simple terms using two sources of raw materials and a market. He by presenting his theory in 1882, considered industrial optimal location as a place where the total cost of transporting raw materials, finished goods and fuel sources, is minimal. But the first one which made helpful and extensive review about the theory of industrial location was Alfred Weber. Weber's original idea was that the firm will choose a place for him that minimal the cost of production. Weber believed that three factors are effective in facility location:

A) The cost of transport

B) Labor costs

C) Staff who cause concentration or dispersion.

Weber named two first factors which means Cost of transport and Labor costs as a general factor and named third factor which is Staff who cause concentration of dispersion (accumulation or non-accumulation) as local factor. By presenting his theory in 1909, foundation of his idea was to minimize the cost. After World War II, the emergence of theories will have to rely on the market. "Analysis of the market areas" is one of these theories. Since buyers are scattered in a wide range of country and applicants density varies from place to place, so the industry will be deployed far more demanding. For this reason, some experts consider market factor as the main factor of industrial facility location. August Lösch German economist found that the optimum location for industry, is the location of the most efficiency, where income is greater than expenses. Lösch was including those that place consider the optimal location as a performance of market demand. If a third procedure would be found in the theories of location then it is min-max theory that its creator is (Green Hot). In his opinion, the optimal location for the industry deployment is a place where the two curves of expenses and income has the highest distance away from each other. In the study procedure of theory of location, will encounter to replacement or substitution theory. Which means by recognizing the factors of production, we can achieve the goal of minimizing earlier factors to replace these factors and again in continuing the theory of location, using linear programming in theory of location can be seen that during it a place not important but the industry in important to select the proper and the best assessment in different locations.

\section{Location Analysis}

Facility location in recent years is known as one of the key elements in the success and survival of the industrial centers. Facility Location both nationally and internationally is highly regarded. The identification of targets and methods to solve location problems is of great importance.

Facility location is one of the industrial engineering sciences that could reduce the cost and create success of the industrial units. Locate centers (locate buildings and centers) is known for selecting a location for a single or multi-centers by taking into account other centers and existing limitations, so that a particular purpose could be optimized. This goal could be shipping cost, fair service delivery to customers, taking the biggest market, and so on. Facility location need expertise, including operations research, decision-making methods, geography (geology and climate), engineering economics, computer science, mathematics, marketing, design etc. Making decision about the location is of certain factors and methods that makes the best possibility for specifying and selecting the optimum location in the hands of decision makers. By increasing the intensity of competition, providing services in proper places and locations of clients favor is of decisive factors in attracting and keeping customers, so service institutions, including insurance companies are about to establish branches in different regions to have a wide range of covering regardless of presenting better services [3]. If effective factors in creating activities in region level would be examined in implementing a successful location and proper places would be given to managers and final decision makers as the output of location process, these 
individuals will select appropriate options on the basis of existing policies and priorities of each of results. Economic efficiency is also considered in facility location, implementing projects in selected locations avoid wasting investments in inappropriate locations in addition to achieving the expected performance and lead to achieve economic profit [4]. Facility location may be done at two levels:

(1) Single location: in a single location, location of (place) facilities will be determined, such as locating a factory in one country, determining the location of a dam across a river or locate a base in one area.

(2) Compound location: In this case, several locations of facilities at the same time will be determined, such as locating several factories in the country or locate several depots in the country [5].

Selecting the location is an important factor in activity of economic firms. Location-based science due to this importance seeks to provide improved methods and techniques to determine the location and activities of firms. Spending exorbitant fees in order to create economic firms and also considering communication and ease of access, indicates the importance of precise location and determination of proper location for this group of entrepreneurs in which allows easy and quick access for most citizens of these firms.

This necessity becomes evident when the process of population growth and the consequent growth of the city and increasing the price of the location and also the lack of equal distribution of the population in various parts of the city would be taken into consideration. Facility location is influenced by qualitative and quantitative factors that require the use of different methods of planning and decisionmaking. In order to identify factors associated with locating, these services are required to first consider principles and assumptions that affect the spatial behavior patterns of customers and managers of related organizations. Thus spatial behavior patterns can be considered as a set of behavioral relationships which according to it, a customer goes toward a facility to reach a service or a company use it to provide services based on specific location. According to the definition said above, there are two different dimension in spatial behavior pattern which are the customer and the company or service provider company managers [6].

(a) Customers spatial behavior patterns:

Customers' spatial patterns views are based on a set of normative assumptions of customers. Accordingly, the simplest assumption in identification of the process of selecting a facility by customer, is the nearest center hypothesis [7].

(b) Spatial behavior patterns of companies or managers of the service provider company:

The most basic principles that will be in consideration of the economic organizations and institutions managers especially profit organizations in location is economic principle or cost-benefit principle. Accordingly, the first target on managers in locating is maximizing profits and minimizing costs or the concept of performance. In the area of location decisions, the concept of performance becomes relevant in occasions that demands for facilities have dynamic nature [6].

In spatial behavior pattern, standards of synonymous distance with the concept of accessibility is used. According to Bach four general principles focuses on accessibility which are:

Principle 1: minimizing the total distances between one service or activity and its customers

Principle 2: The maximum allowed distance of customers to a service

Principle 3: maximizing the use of a facility.

Principle 4: Choose the best location that cam attract maximum allowed distance to a customer [8].

\subsection{Location Objectives}

Location problems contain different objectives. The objectives play an important role in identifying and prioritizing decision criteria in a location problem and its sub-criteria. In one division [9], the purposes of location problems with mathematical programming approach and in terms of the objective function are divided into three categories:

(1) Pull objectives: these objectives refer to the proximity to the customer's settlement location and lessen the distance between which include the oldest location problems. In fact, those problems that their objective functions are minimization have pull objectives.

(2) Push objectives: these objectives consist of undesirable location centers problems and were created on the early 1970s. The objective of these problems is to maximize the distance of new centers from existing centers. Models that were presented for these kind of objectives later on were known as hazardous location models.

(3) The balancing objectives: are such objectives that attempt in balancing the distance between the centers and customers. These objectives are always the most continues objectives and their main purpose is to achieve equality. These objectives are used mostly in public decision-making, where the aim is to establish justice among people.

\subsection{Types of Location Problems}

Location problems are very diverse, hence for ease of expression, these problems have been categorized in several ways, but spatial analysis problems generally are categorized in one of the following categories:

(1) P-Median problem (the Weber problem): The sort of problems use to locate central $\mathrm{P}$ in $\mathrm{P}$ location and minimum a benchmark cost. If $p=1$, then problem 1 will be MP. The cost might be expressed in terms of time, money, number of travels, total distance or any other scale. Because the objective of these problems are to minimum the total cost therefore raised as Mini Sum problem or Weber problem as well.

(2) P-Center problem: this problem is used for center of $\mathrm{P}$ 
location in order to minimize the maximum distance of each center to the demand center which is determined to give service to that point. The number of centers in these problems are known in advance. These problems are divided into two categories. Convex P-Center limit the problem to a set of location candidates to deploy and absolute p-center where centers can be deployed anywhere in the area.

(3) Incapacitated facility location problem: (UFLP) these problems are placed in Min Sum category, but fixed costs are included in cost problems and fixed costs are dependent on the location where the center is based. The number of centers that need to be deployed are not pre-specified, but are given a way to minimize that cost. Due to unlimited considering of capacity of each center in these problems, allocating a demand to supply more than one point will never be profitable.

(4) Incapacitated facility location problem: (UFLP) These problems are similar to UFLP problems but capacity of each center in these problems are limited. May be the optimal solution in this case be in the way that a customer is referred to more than one source of supply. In fact after allocating a customer to a center, the capacity of the center may come to an end after meeting a part of customer demand and to meet the rest of customer demand it may be required to assign it to another center that has more cost. Although it sometimes whether it takes the least cost to a special center when a customer is assigned to, it is forced to devote the whole demand of that customer to other centers because the capacity of that center is filled by other customers.

(5) Exponential allocation problems: it expresses a problem that $\mathrm{n}$ centers like $\mathrm{n}$ machine that there is a connection between them, place into $n$ location that minimize the total cost. If there are 4 machines for deployment, there will be four possible combinations. For 20 machines, there are 20 possible answers which about $1018 * 2$ assessments will be required that is difficult even for today's fast computers. Hence, these problems are in very complex category and solving them either would be so difficult or impossible.

Some elements are important in facility location problems category. The facility location problems in fact in addition to being classified in mentioned category, it can be classified into different categories such as the P-Median problem with limited demand and the P-Median problem with unlimited demand. Thus, during categorizing facility location problems, elements such as new centers, location of existing centers, interaction between new and existing centers, specific solution space, distance, combination with other problems, demand, capacity, type of centers, deterministic and probabilistic of data type, the frequency of execution, product diversification and objective function should be taken into consideration. The facility location problem is usually a multi-criteria decision making problem that have these requirements:

(1) There are m number of candidates to choose which location should be chosen among $\mathrm{m}$.

(2) There are n number of decision-makers that should be considered in location selection. These criteria usually behave in the opposite direction as well. This means that the possibility of reducing an indicator in case of increasing the other.

(3) Comments and assessments of a $\mathrm{k}$ member group of decision-makers should be considered in choosing locations.

In addition, due to the difference in members of the decision-making group in terms of experience and knowledge and their influence in decision-making, the role and importance of the views of each of these decision makers will be different from others.

\subsection{Common Mistakes in Facility Location}

Making a mistake in locating will follow irreparable harm and sometimes lead to change in location with increased costs or lead to stagnation and a total shut down of location project. Generally, mistake in determining the location, occurs when a well definition of what is required is not available. But there are other mistakes that even shrewd managers are also affected. Some of these mistakes as a heads up to managers, researchers and key persons and decision making on facility location problems is expressed as follows:

(a) Lack of inspection and a detailed description of the factors and requirements.

(b) Partial waiver of some requirements and incomplete review of design requirements.

(c) Personal interests or prejudices of the authorities in accepting logical and scientific facts and reasons.

(d) Resistance of executive managers in transition to the new location.

(e) Too much attention to crowded areas and industrial zones resulting in ignoring the newly industrialized or are on the verge of industrialization.

(f) Too much attention to the cost of lands and resulting in choosing cheap or free lands.

(g) Ignoring shipping cost and failure to meet it right.

(h) Judging potential human resources based on fee rates and regardless to efficiency, skills, history and labor history and other important factors in selection of human resources.

(i) Choosing a society with a low level of culture and education in a way that is very difficult to attract skilled workers.

(j) Insistence on immediate and short-term interests and neglect the future.

(k) Insufficient or incorrect information about market, methods of transportation, raw materials and other factors that affect cost estimate.

(1) Environmental factors including political pressures.

(m) Errors in using methods and techniques in facility location decision.

(n) Lack of proper prioritization (balancing) of decision criteria.

(o) Lack of accurate and sufficient information on desired criteria.

(p) Disregard the strategic and long-term effects of 
location decisions.

(q) Disregard the change and future developments (threats, opportunities, growth in demand, location balance disruption, etc.)

(r) Ignoring organizational changes that are necessary to locate.

(s) The aforementioned factors obtained are based on the authors' experiences in numerous projects of facility location and analysis of failure causes of some industrial centers. Given enough attention to those factors will reduce the risk of decision making on facility location projects.

\section{Facility Location in Insurance}

Insurance companies in Iran are encountered with the problem of inadequate coverage of the market and lack of physical effective distribution in the country. Choosing a proper facility location for the establishment of branches and agencies of private insurance companies means reduction in administrative costs and increase company revenue. Insurance branch location placing is important because it determines the amount and ease of access to insurance services; as more areas are covered, more potential customers place in range of branch attraction. On the other hand the costs of displacement to get to branches are reduced, the number of insurance customers visitations increase and customers benefits from more services. However, even with providing the best service with excellent quality, if a proper location to provide services cannot be found then failure is encountered which means lack of profitability and leaving the industry.

Lots of factors in selecting the optimum service location should be considered. Depending on the type of services and intended market, a number of these factors are include: the price of labor, estimates of available market areas, potential customers, access to suppliers, environmental problems and social considerations [10]. Since e-commerce in most advanced communities in last decades have a significant share of transactions in most daily exchanges and all predictions indicate stronger growth in upcoming years, the concept of facility location for institutions such as insurance companies and banks which most of their exchanges are often done via the internet, is affected on the presence of ecommerce; for example in the insurance industry, insurance agent after completing a form on the website of the insurance company by the customer and completing a type of insurance application form present to location in order to assess the status of the contract; so a customer rarely refers to the insurance companies and this subject reduce the sensitivity of insurance companies in selecting locations and branches and mostly put economic purchase considerations into consideration; But due to the lack of growth in e-commerce and the general lack of adequate access to the Internet in Iran, branches location and agencies of an insurance company can effect in selling all types of insurance tariffs [11].

Liang \& Wang after concluding factors in articles and studies, classify all effective factors in selecting the location as follows:

\section{(a) Vital Factors}

All social or security considerations factors or technical and economic criteria that managers consider, who determine solely that a location should not be chosen are placed on this class.

(b) Objective Factors

All factors that can be expressed with few terms are considered as objective factors. Comparison of these factors in the various options in terms of decision-makers, have single concept.

(c) Subjective Factors

These factors are qualitative and mostly based on subjective estimates of decision-makers. Qualitative or subjective objectives are ones that cannot be included directly in the form of figures, but with traits such as low, high, good and bad can be assessed or the comparison of this evaluations are determined. Evaluation of these factors is strongly influenced by the perceptions and experiences of decision makers. Therefore any method or model among different decision-making methods that can include both subjective and objective factors is appropriate for using in selection of optimum establishment of agency location.

Facility Location of Insurance Branches Using the Concept of Fuzzy Logic

Facility location of insurance branches using the concept of fuzzy logic has been accomplished by followed executive stages for formulation of optimum facility location method based on fuzzy logic:

(1) First Step

The purpose of implementing of this step is to identify factors affecting the optimal location branches. By implementing this step, the factors that could affect the proper and efficient locating were identified. At this stage, in addition to the literature on facility location with our samples (heads, deputies, experts and employees of the branches of Tehran) and (delegates and experts representing insurance in Tehran) are interviewed to identify key factors affecting the optimal facility location which eventually after interview with the groups of statistic samples and the study of literature related to the facility location, hypothetical factors affecting the optimal would be extracted.

(2) Second Step

Since factors identified in the first step are hypothetical primary factors affecting the optimal location branches, thus the second step in order to analyze the perspective of experts (Group of statistic population) carried out about identified factors. Implementing this step ensures that how much the agents identified in the first step are "influencing" factors to optimal implementation facility location of branches.

Input to Step (2):

Factors affecting the optimal location identified in the first step.

Output from Step (2):

Categorization, classification and analysis of the identified factors in the first step that extracted from questionnaire is included in the following table. 
Table 1. Factors influencing the optimal identified facility location.

\begin{tabular}{|c|c|c|c|c|c|c|}
\hline \multirow{2}{*}{ NO. } & \multirow{2}{*}{ Factor affecting the optimal location } & \multicolumn{5}{|c|}{ Effectiveness } \\
\hline & & Effectless & Low effect & Normal effect & effective & Very effective \\
\hline 1 & Proximity to highway & & & $\checkmark$ & & \\
\hline 2 & Proximity to intersection & & & & $\checkmark$ & \\
\hline 3 & Building (extent) area & & $\checkmark$ & & & \\
\hline 4 & Proximity to institutes and government agencies & & & & $\checkmark$ & \\
\hline 5 & Proximity to residential areas & & & & $\checkmark$ & \\
\hline 6 & Separation from parent company branches & & & & $\checkmark$ & \\
\hline 7 & Proximity to parent company agencies & & & & $\checkmark$ & \\
\hline 8 & Proximity main street & & & & $\checkmark$ & \\
\hline 9 & Proximity to city's main squares & & & & $\checkmark$ & \\
\hline 10 & New construction & & & & $\checkmark$ & \\
\hline 11 & Proximity to banks and credit institutions & & & & & $\checkmark$ \\
\hline 12 & Proximity to freights & & & & $\checkmark$ & \\
\hline 13 & Separation from crowded malls and high traffic & & & & $\checkmark$ & \\
\hline 14 & General culture in the region & & & & $\checkmark$ & \\
\hline 15 & Separation from agencies and branches of other companies & & & & $\checkmark$ & \\
\hline 16 & Separation from traffic plan streets & & & & $\checkmark$ & \\
\hline 17 & Located on the corner of street & & & & $\checkmark$ & \\
\hline 18 & Proximity to industrial centers & & & & $\checkmark$ & \\
\hline 19 & ground floor building & & & & & $\checkmark$ \\
\hline 20 & Proximity to headquarters offices of factories & & & & & $\checkmark$ \\
\hline 21 & Proximity to entrance or exit of the city & & & & $\checkmark$ & \\
\hline 22 & Proximity to parking lot & & & $\checkmark$ & & \\
\hline 23 & Proximity to car repair shops & & & $\checkmark$ & & \\
\hline 24 & $\begin{array}{l}\text { Proximity to public transportation such as subway terminals, } \\
\text { Park \& Ride, terminals }\end{array}$ & & & & $\checkmark$ & \\
\hline 25 & Proximity to parent company & & & $\checkmark$ & & \\
\hline 26 & Amount of people income in region & & & & $\checkmark$ & \\
\hline 27 & Facade & & & & $\checkmark$ & \\
\hline 28 & Proximity to two-way streets & & & & $\checkmark$ & \\
\hline 29 & Proximity to commercial centers and sales of goods & & & & & $\checkmark$ \\
\hline 30 & Proximity to carwash & & & & $\checkmark$ & \\
\hline 31 & Communication channels & & & & $\checkmark$ & \\
\hline 32 & Population & & & & $\checkmark$ & \\
\hline
\end{tabular}

\section{Conclusion}

In this study, we tried to introduce key factors to select the optimal location of deploying insurance branches to facilitate the possibility of group decision making in selecting the optimum location, because it was induced to believe that:

(1). The process of selecting the current location of the branches, not a rigorous and comprehensive process.

(2). The current location of universal branches does not contain maximum characteristics and properties of optimal location.

(3). Perspectives of various groups and stakeholders is not included in selecting current branches locations.

Also, since different groups of stakeholders effect on selecting location, it can be said that that the made decision has a lot of integrity.

Also, since we cannot judge a location to deploy branch by using the words "fully optimized" or "fully unoptimized" instead we can use terms such as "somewhat optimized", hence fuzzy logic is used to indicate the amount of optimization of a location to deploy branches in range between zero and one. So the optimality of a location is possible to be between 70 out of 100 and another location is 65 of 100 points. Finally deciding maker select a location for establishment of branches that have the most optimality points. Insurance companies using the analysis of the key factors in this paper, can choose the most suitable location for its branches.

\section{References}

[1] Niknam, Omid Ali. (1385). Formulation of appropriate decision making for optimal locating of insurance agencies deployment using fuzzy logic-based approach, Journal of the insurance industry, Fall, No. 83, 29-50.

[2] Schmid, V., and Doerner, K. F. (2010). Ambulance Location and Relocation Problems with Time-dependent Travel Times. European Journal of Operational Research, 207(3), 12931303.

[3] Mottaghi, Hayedeh. (1383). Production and operations management, Kiumars publication.

[4] Mahdipour, Fatemeh. (1380). A pattern for locating based on multi-criteria decision-making methods in GIS, GIS master's student paper, Khajeh Nasir University.

[5] Parhizgar, Akbar. (1376). Presenting proper pattern for locating urban service centers, Ph. D. Thesis, Tarbiat Modarres University. 
[6] Jiaxi, L. (2003). Multi Functional Parking Facility site selection in tourist towns: A case study of Chang yang, China, M. S thesis International Institute for Geo Information science and earth Observation.

[7] Craig, C. S., Ghosh, A., and McLofferty, S. (1984). Models of retail location process: a review, international Journal of Retailing, vol.60, no. 1.

[8] Bach, L. (1980). Location models for systems of private and public facilities based on concepts of accessibility and access opportunity, Environmental and planning (A), no 12.
[9] Drenzer, Z. V. I. (1995). Facility location: A survey of applications and methods, Springer.

[10] Finch, B. J. (2003). Operation prices (value, and profitability), McGrave Hill, New York.

[11] Meshkani Farahani, Leila. (1385). Presenting locating for car insurance agencies pattern based on the opinions of Parsian bank insurance experts using Analytical Hierarchy Process (AHP) approach, Master's thesis, Tarbiat Modarres University, Faculty of Humanities. 